Case for Teaching

\title{
Pandemic, Samba, and Diogo Nogueira's Livestreams: Platform Management Challenges
}

\author{
Pandemia, Samba e as Lives de Diogo Nogueira: Desafios de Gestão de \\ Plataformas
}

Discipline: Strategy

Subject: Innovation Management, Digital Media

Industry: Art and Entertainment

Geography: Rio de Janeiro/Brazil
Marco Aurelio de Souza Rodrigues ${ }^{1}$ ৫

Daniel Kamlot ${ }^{2}$ (e)

Anita Vasconcelos de Carvalho ${ }^{10}$

\section{INTRODUCTION}

On his birthday, in April 2020, Diogo Nogueira woke up, opened the window and gazed at the sky, realizing he had received a special gift: a beautiful sunny Sunday, one of those days that deserve to be enjoyed slowly and at home... accompanied by a lot of music, friends, and good food.

That feeling filled Diogo's heart and, momentarily, that birthday seemed to be just another day of celebration among so many that life generously brings. But the sensation was short-lived. On the guitar, someone played a sad song turning Diogo's attention from the sky to the backyard of his house.

1. Escola Superior de Propaganda e Marketing, Rio de Janeiro, RJ, Brazil.

2. Fundação Getulio Vargas, Escola Brasileira de Administração Pública e de Empresas, Rio de Janeiro, RJ, Brazil.

Cite as: Rodrigues, M. A. de S., Kamlot, D., \& Carvalho, A. V. de (2021). Pandemic, samba, and Diogo Nogueira's livestreams: Platform management challenges. Revista de Administração Contemporânea, 25(spe), e200225. https://doi.org/10.1590/1982-7849rac2021200225.en
There were cameras, equipment, and friends technicians and musicians, friendships built throughout his career. They were there to congratulate him and to face a new challenge: to celebrate the artist's birthday through a livestream concert, in which thousands of fans would participate in the preparation of a beautiful moqueca, accompanied by samba songs of the highest quality.

The WhatsApp rang. "Wake up, Diogo," thought the artist when looking at the screen: "Wow!... Eight in the morning... three missed audio messages from Afonso!" Afonso Carvalho and Anita Carvalho are entrepreneurs and the managers who take care of Diogo's career. Afonso's audios said: "Happy birthday, Diogo! Woke up late? Don't forget, the livestream concert begins at noon!"

$\sum_{0}^{1}$


The audio messages made Diogo wake up for good, reminding the artist of that dreadful Friday that changed his life, the thirteenth of March of 2020, when a contractor called to announce the postponement of that night's concert. It would be the first of many calls asking for postponements, all justified by measures of social isolation brought about by the rapid spread of COVID-19. Afonso, Anita, and Diogo were experienced in the music market, but this time they were dealing with an unprecedented situation: a pandemic that forced the prohibition of agglomerations and, therefore, prevented concerts to be held. It was necessary to think quickly about strategies to keep the artist in evidence during this period of isolation and create alternative sources of revenue.

Diogo recalled the initial market reactions to the pandemic. At the end of March 2020, artists started promoting their livestream concerts, that is, live performances through platforms such as YouTube, obtaining mixed results. Although some livestream concerts reached a large audience, there were a small but growing number of critics. Not infrequently, comments on social networks pointed out how those concerts exposed musicians to the risk of contamination by COVID-19. And, sometimes, popular artists overdosed on alcohol during performances, tarnishing their own image and the perception of the public and sponsors concerning the livestream concerts in general. As a result, these incidents raised in the market a discussion about a possible increase in regulation on the exposure of brands in this type of transmission.

Despite these setbacks, Diogo, Anita, and Afonso decided to bet on livestream concerts. And in their debut in this format, they established an innovation: they would position the concert at lunchtime on Sunday, as if it was a meeting of a large family that would gather to celebrate Diogo's birthday. The artist would 'virtually' open his kitchen to friends and family and prepare a tasty meal to enhance the event. And seizing the opportunity, a digital cookbook signed by Diogo Nogueira would be launched throughout the livestream concert.

To come up with the idea, the trio had just over a month to solve challenges related to the participants' safety, the monetization of the event, and the development of skills that, until then, they did not master: "Suddenly I had to learn to be a samba player, a TV presenter and a youtuber...," thought Diogo. A sad song came out of the guitar again and Diogo asked himself: "What about today's livestream concert... will it work?”

Despite the feeling of nervousness and the importance of the debut, Diogo, Anita, and Afonso understood the great challenge was not limited to the success of this first transmission. In fact, the trio reflected on the sustainability of the livestream model as a whole. In a world where the artist cannot meet his audience, the model of live paid concerts was quickly replaced by a new 'standard': free concerts distributed by YouTube. However, the very originality of livestream concerts brought uncertainty: Would there be enough demand from sponsors and viewers, given the dissemination of livestream shows in the market? And could the regulation on brand exposure in livestream concerts become more stringent?

Considering such uncertainties, should Diogo and his managers continue to 'bet' on the model of free livestreams distributed by YouTube? Or should the trio consider new commercial models for their livestream concerts?

While Diogo reflected on this dilemma, the morning passed quickly. In the space improvised as a dressing room, someone knocked on the door: it was Afonso, warning there were 10 minutes to go on air. Diogo went to the kitchen to start the preparing of the moqueca and the livestream concert. Looking at the camera, he said: “'The sleepy shrimp will be taken by the waves,' the poet used to say! Let's stop crying because now is the time for us to dance!"

\section{BACKGROUND}

During the pandemic that started in March 2020, livestream concerts, or simply lives, as they are referred to in Brazil, became popular as an unpretentious format for free distribution of live musical shows. Artists like Chris Martin (from the band Coldplay) broadcasted from their homes on their own to encourage people to stay home and donate to charity. In Brazil, livestream concerts have become superlative: audiences have grown, reaching a record of 3.3 million simultaneous accesses during the broadcast of one of the country's most popular singers, Marília Mendonça. Due to their reach, the lives aroused the interest of advertisers, who recognized in the format an efficient way to contact consumers with low confidence in the economy and low tolerance for commercial breaks. And many livestreams shows are accessed after the live exhibition, giving great exposure to the artist.

However, initially, the growth in the number of viewers (spectators) was faster than the increase in the professionalization of lives. Over time, reports of artists breaching recommendations for isolation, showing inappropriate behaviors, or even lives that were interrupted by failures in the internet infrastructure have accumulated. Thus, "advertisers started to worry a lot about technical aspects before sponsoring a livestream concert," said Afonso. Producing a live capable of simultaneously attracting both the public and advertisers has evolved from a process in which a stool, a guitar, and a smartphone with internet connection were enough into a challenge of great technical, artistic, commercial, and sanitary complexity. 
Thus, the realization of Diogo Nogueira's birthday live was the culmination of a difficult adaptation process that began on March 13, 2020, when Brazilian regulatory agencies announced measures of social isolation aimed at combating the COVID-19 pandemic. Diogo, Anita, and Afonso had a few weeks to react to an event that actually paralyzed all their operations. In view of the uncertainty about how long agglomerations would remain prohibited, the artist and his managers decided to produce their first live, despite the complexity involved in the process. Afonso knew that, even if they managed to get sponsors for Diogo's first live, the artist's performance in his debut in this format would be fundamental for business continuity during the pandemic. A failure to broadcast the event or even a musician too close to a colleague could generate controversies that would damage the artist's image among fans and make it difficult to prospect for advertisers in the future. Considering the grief that many families lived during the pandemic, even subtle details such as the correct 'tone' of the joy that should be transmitted through the live were considered: "We were reticent to make lives for fear of showing 'joy' in the middle of the pandemic, but then we understood that it would be a way to bring relief to people in a context of dismay," said Anita. On the other hand, if Diogo's live was a success, it would attract new fans who, in turn, would make the artist more interesting for new sponsors. Success depended on a tricky balance, as Afonso recalled: "On the one hand, we need to meet safety criteria, do tests for COVID, increase hygiene ... which cuts our team in half." Anita added: "At the same time, we need to excel in the technical aspect, because we have to think about things like capturing images, cameras, cranes, teleprompter, sign language for the hearing impaired, dedicated internet lines because the connection can drop at any time... These are things that are not native to live concerts." And Afonso also quoted: "And, in the creative aspect, we have to think about a new entertainment model. It's not just a concert. A livestream concert is like a live TV show, you can't miss the timing... We have to synchronize guest stars appearances in real time, we have to think about how to entertain three million people for four hours! Lives have no commercial breaks... we have to consider the musician's tiredness. And we cannot forget the haters: I have seen lives that, before they started, already had hundreds of dislikes... We have to be careful with Diogo's public figure..."

So the challenges were great and the stakes were high. Afonso had in mind long-time partners who could sponsor the live, but he was not sure if they would indeed be interested. At the beginning of the year, Anita coordinated a survey that indicated the profile of Diogo's fans: predominantly female, between 35 and 55 years old, with monthly income between two thousand and ten thousand Brazilian reais $(\mathrm{R} \$)$. In this research, it was found that Diogo was associated by the public with joy, samba, and love. Could this data help Anita and Afonso in their search for sponsors? In parallel, Diogo Nogueira's digital recipe book was being produced at a swift pace. The idea was to launch it during the live held on April 26 through 'pre-orders' for $\mathrm{R} \$ 25$, taking advantage of the proximity of Mother's Day (which, in Brazil, occurs on the second Sunday of May).

\section{DIOGO NOGUEIRA}

Singer, composer, surfer, and a renowned samba player, Diogo Nogueira wanted to be a football player, but an injury took him off the fields. As a result, Brazilian music won a musician who earned six gold albums, three gold DVDs, two platinum and one double platinum DVDs, in addition to the Latin Grammy Award, a prize obtained twice.

In 2020, with a 13-year career, he was one of the main names in Brazilian samba. Son of one of the greatest samba singers in the country, João Nogueira, Diogo grew up lulled by choro songs, sambas, and a lot of drumming in songs composed at home by his father with the creme de la creme of the samba. A multimedia artist, he debuted as an actor in the musical 'SamBRA', which marked the beginning of the celebrations of the centenary of samba. He also acted as a host for the program Samba na Gamboa (the largest audience on TV Brasil). He commanded the Batukada Boa, a weekly radio program, with a live samba circle on Rádio Transcontinental. Without much fanfare, he sang four samba plots for his samba school, Portela, all of which earned perfect scores from the Samba Schools' Parade judges.

\section{MUSIC INDUSTRY IN BRAZIL}

The importance of the music industry becomes clear when put into data: in 2018, 40,000 live concerts were performed in Brazil, with total revenue estimated at around US $\$ 450$ million. In the same period, revenues from recorded music in Brazil reached around US\$ 300 million. Globally, it was projected that in 2020 live performances would reach revenues of US\$ 28 billion, while recorded music would reach US\$ 20 billion. Despite this strength, the Brazilian music market was strongly impacted by COVID-19: it is estimated that more than 8,000 events were postponed or cancelled, affecting eight million people with an estimated loss of R $\$ 483$ million. 


\section{STREAMING PLATFORMS IN BRAZIL AND THE WORLD}

Streaming is the term by which the simultaneous transmission and display of audiovisual content is known. In this model, the consumption of content does not require a prior download, which makes access faster and more functional. In 2019, about $86 \%$ of music consumers used streaming services, with Brazil occupying the third position in the ranking of the largest users in the world.

In fact, in that year, the Brazilian music streaming market showed expansion, generating approximately US\$ 276 million in revenue, an $18 \%$ growth in relation to the previous year. Still in 2019, Brazil registered 31 million users of streaming music who, on average, invested seven hours a month in this type of entertainment, $80 \%$ of which occurred on mobile devices. Estimates suggest that Spotify had the leadership of the Brazilian market in this period, with $58 \%$ of these users, followed by Deezer, with $15 \%$.

Worldwide, Spotify held the leadership in 2020, accounting for 286 million users, of which 45\% corresponded to paid accounts, with the remaining free accounts maintained through advertisements. Spotify accumulated $35 \%$ of paid subscribers worldwide, followed by Apple Music (19\%), Amazon Music (15\%), and YouTube Music (6\%).

For many consumers, however, a video streaming service was their primary destination for listening to music: YouTube. About one billion users visited YouTube monthly to consume music. Estimates indicate that YouTube alone accounts for $46 \%$ of the time dedicated to consuming music through streaming in the world.

In addition to being the favorite destination of many users for music consumption, in 2020 YouTube was considered the largest video streaming platform in the world, surpassing two billion active monthly users who, daily, viewed more than one billion hours of content, $70 \%$ of which were consumed on mobile devices. However, it seems that YouTube is gradually being consumed outside these devices as well, gaining space on SmarTVs in users' living rooms. In Brazil alone, YouTube reached around 150 million users in 2020 .

Despite the expansion of the streaming model, which many considered favorable for the music industry as a whole, there was a growing questioning about the value of royalties paid to the artists for reproduction. Such values, considered insufficient by many, have, in extreme cases, resulted in boycotts of artists and users on certain platforms.

\section{THE PHENOMENON OF LIVES}

The COVID-19 pandemic has turned lives into a worldwide phenomenon, leading them to undeniable importance in the most diverse spheres of daily life. The music industry, which agonized with the ban on agglomerations, was largely responsible for popularizing the format, aiming not only to bring entertainment to the audience that was at home but also to allow professionals whose source of income depended on live shows (that used to gather thousands of people) to keep working.

If, on the one hand, the health crisis highlighted the difficulties of the artistic sector, on the other hand it opened up opportunities that had not been fully explored before. The spread of festivals and live music performances on digital platforms seemed to be the main way that artists found to pursue their careers. In addition to reinforcing the importance of social distance and entertaining the masses, lives maintained awareness about artists, who were considered brands of interest to the consumers.

Lives took on various forms of monetization. Wellknown artists, such as Billie Eilish, have successfully experimented charging for tickets that grant access to livestream concerts broadcasted on their own websites and apps $^{1}$. Other prominent artists, such as Melissa Etheridge, were successful in offering their lives in their own apps upon subscription ${ }^{2}$.

However, the usual monetization model was the association between brands and artists in virtual performances through sponsorships. In this model, brands linked their images to renowned artists to connect with the public. The greater the artist's popularity, the greater the brand's interest in paying for large sponsorship quotas to connect with consumers.

The Brazilian public seemed particularly fond of lives, so much that searches for this type of content grew 4,900\% in the country during the beginning of the period of social isolation. As a result, sponsorships of lives produced by popular artists in Brazil achieved expressive values quickly, reaching about $\mathrm{R} \$ 500,000$ in lives capable of attracting millions of simultaneous viewers ${ }^{3}$.

The format of the lives has as its main differential the unusual combination of a great audience reach with a more direct and intimate contact with the public. However, the challenges are also diverse, ranging from issues regarding digital rights management to an eventual oversupply of livestream concerts, which started to show signs of a drop in audience in mid-2020. 


\section{DIOGO'S LIVE RESULTS}

In the third 'encore,' the last notes of the song It Was a River That Passed in My Life were played with care by the musicians, as a final effort to perfectly close the live that lasted for three hours successfully. At the end, Diogo was apprehensive... As soon as the camera was turned off, he looked at Afonso and Anita and asked: "How was it?"

"A success!" they celebrated. "We are still consolidating the results from social media... But we collected 17 tons of food in donations, and we obtained, only in sponsorships, two and a half times the normal fee for a standard offline live concert... with brands of national relevance!" said Afonso. "What about the cookbook?" asked Diogo. "More than 1,000 purchase orders!" celebrated Anita. "And the moqueca, did you taste it?" joked Diogo.

Amid the laughter, a young analyst from the team responsible for managing Diogo's presence on social media entered the kitchen. Everyone looked at each other, waiting for the news... "Speak, man!" said Diogo. The analyst celebrated: "We got two million and 700 thousand views!!! With a peak of 550 thousand simultaneous accesses!! We came first in Twitter's trending topics and second in YouTube! And we increased the number of subscribers on our YouTube channel by 100 thousand: We now have 600 thousand subscribers!!”

\section{NEXT STEPS}

The success of Diogo Nogueira's birthday live touched everyone in the kitchen, spreading a sense of accomplishment. Diogo, however, knew it was not time to relax... They had won a battle, but there was still a war to be fought.

As Diogo Nogueira's birthday broadcast demonstrated, a sponsored live represented a revenue source comparable to major concerts. However, while artists like Diogo can do about four shows a week, it is not known if there is enough demand for weekly or monthly lives, which may make this format less interesting comparatively. Thus, Diogo, Afonso, and Anita wondered what would happen to the demand for lives throughout the period of social isolation and in the post-pandemic world. Would the public demand for this type of entertainment continue? Or would lives become an offer consumed only by the most loyal fans? In addition, popular singers inappropriately consuming products from sponsors during the broadcasts sparked a fear that regulatory changes could quickly compromise the monetization model of lives.

"The problem is that, in this context in which we cannot have crowds at shows, we do not know how long lives supported by sponsorships are sustainable," said Diogo. "We already have other sources of revenue linked to lives, such as ads that precede the transmission, but they generate very fragmented and small revenues," he added.

Thus, despite the success of this first live, a fundamental dilemma still remained in the mind of the artist and his managers, in view of the uncertainties inherent in an environment that combines the prohibition of live concerts with technological transformations: What would be the best way to Diogo to continue commercializing his lives?

The trio had focused on this issue over the past week, considering alternatives to generate revenue from lives. An alternative was simply to maintain the current model, in which sponsored lives promoted, in a complementary way, Diogo's other artistic talents. Diogo realized how livestream concerts were technically similar to live TV shows. Thus, he wondered if he could keep using the commercial model established by TV shows, which uses its content to promote other offers. In this sense, the launch of the cookbook during the birthday live could be understood as a prototype of something bigger. Besides the cookbook, what other content could be promoted through Diogo's lives?

Other more daring alternatives came from an outsider. On the eve of Diogo's live, the artist's manager, Afonso, was talking to Fagundes, a friend who used to invest in startups, about the evolution of lives. Fagundes asked: "Aren't you concerned about the dependence artists are developing on platforms like YouTube? Just a change in its monetization or production rules would directly affect all livestream concerts! And look, it wouldn't be the first time this has happened!" The investor was referring to previous changes made by YouTube, as well as rumors that there would soon be changes in the rules regarding the exposure of brands in YouTube videos.

At that moment, Fagundes recalled that foreign stars, such as Billie Eilish, Melissa Etheridge, and Erikah Badu, launched their own apps or websites to distribute their lives in order to improve their remuneration and reduce their dependence on streaming platforms. He added: "What if Diogo creates an app for paid lives? If we offer exclusive content at a good price, maybe we can make the lives more interesting for Diogo. Maybe he could even invite other samba singers to participate!"

Initially, Afonso found the idea completely crazy and replied: "How am I going to create a brand new app? Imagine the cost of that!" Fagundes replied: "It is less complicated than it looks!" He then explained how these music stars launched their own streaming apps by hiring 'software as a service' (SaaS) providers that market 
customizable ready-to-use apps for a monthly fee or percentage of sales. So, instead of creating an app 'from scratch,' the artist who hires this type of service could customize a ready-to-use app and adopt it as his/her new and exclusive meeting place with the fans, fully capable of distributing paid or free videos. In this way, much of the complexity and initial investment to launch an app would be reduced ${ }^{4}$. Although the negotiations between artists and these 'software as a service' providers varied widely due to the popularity of the stars involved, it is estimated that the use of a customizable app involves paying a commission of around $30 \%$ of the revenue generated. As a reference, the ticket price for lives paid in foreign markets was around $\mathrm{R} \$ 100 .^{5}$

At that moment, Afonso was not convinced: "Are we going to compete with YouTube?!" However, after the exciting debut of Diogo Nogueira in lives, Fagundes' suggestion still sounded crazy, but at least instigating. By coincidence, at that moment, a group of musicians kept their instruments humming Clube do Samba ("Samba Club"), by João Nogueira. "I don't know how to continue our strategy during the pandemic, but if we decide to invest in this crazy app idea, we already have a name for it: Clube do Samba," thought Afonso.

\section{THE DECISION TO BE TAKEN}

At the end of the night, Diogo Nogueira had a lot to celebrate. In addition to the anniversary itself, the live was a victorious first step toward new opportunities. However, the managers and the artist would talk, later that week, about how they should continue Diogo's lives: following the traditional sponsorship model or experimenting with alternative models like those tested by foreign artists? In the background, a last musician insisted on playing a sad song on his guitar...

\section{NOTES}

1. Billboard. (2020). Billie Eilish blows minds with 'where do we go?' Livestream Recap. Retrieved from https://www. billboard.com/articles/columns/pop/9472436/billie-eilishwhere-do-we-go-livestream-concert-recap/

2. Forbes. (2020). Melissa Etheridge's Live streams are pulling in $\$ 50,000$ per month: The artist on doing it her way. Retrieved from https://www.forbes.com/sites/ cathyolson/2020/08/03/13elissa-etheridges-live-streamsare-pulling-in-50000-per-month-the-artist-on-healingconnecting-and-paying-the-bills/\#1cd00bf52f1d

3. Valor. (2020). 'Lives' atraem patrocínio de marcas. Retrieved from https://valor.globo.com/empresas/ noticia/2020/04/22/lives-atraem-patrocinio-de- marcas. ghtml

4. Rolling Stone. (2020). Billie Eilish's virtual concert is the rare livestream done right. Retrieved from https://www. rollingstone.com/music/music-live-reviews/billie-eilishlivestream-virtual-concert-1080748/

5. Billboard. (2020). Here Are all the livestreams \& virtual concerts to watch during Coronavirus crisis (Updating). Retrieved from https://www.billboard.com/articles/ columns/pop/9335531/coronavirus-quarantine-musicevents-online-streams 


\section{Teaching Notes}

\section{ABSTRACT}

This case explores a situation that affected almost all artists - especially musicians - after the COVID-19 pandemic occurred: the need to perform shows in a context where agglomerations are prohibited. Based on the reality of the famous samba singer Diogo Nogueira, a situation is presented in which the decision to make presentations through lives is evaluated. From this scenario, the possible options are exposed for Diogo to remain in evidence before an audience still eager for entertainment. The case makes it possible to discuss strategy, platform management, and innovation. It is recommended to be used in strategy subjects for postgraduate courses.

Keywords: management; platforms; innovation; livestreams.

\section{RESUMO}

O presente caso explora uma situação que atingiu a quase totalidade de artistas - músicos em particular - após a ocorrência da pandemia de COVID-19: a necessidade de realizar shows em um contexto em que aglomeraçóes são proibidas. Com base na realidade do famoso sambista Diogo Nogueira, apresenta-se uma situaçáo em que a decisão por realizar apresentações por meio de lives é avaliada. A partir do cenário vislumbrado, são expostas possíveis opçóes para que Diogo, por meio das lives, mantenhase em evidência perante um público ainda ávido por entretenimento. $\mathrm{O}$ caso possibilita a discussão sobre estratégia, gestão de plataformas e inovação. Recomenda-se a utilizaçáo do caso em disciplinas de estratégia para cursos de pós-graduação.

Palavras-chave: gestão; plataformas; inovação; lives.

\section{Protagonist and information sources}

The case is presented from the point of view of Diogo Nogueira, an artist dedicated to samba. The presence of a famous protagonist, as well as the discussion of a popular innovation (the livestream concerts), tends to favor student engagement. Diogo's vision is complemented by the perspectives of Afonso Carvalho and Anita Carvalho, the singer's managers. The data used in the case were collected between June and October 2020 through in-depth interviews with Diogo Nogueira and his managers, as well as through documentary investigation and bibliographic survey. The interviews lasted about one hour each and aimed to collect information that would allow the students to explore the challenges and opportunities experienced by the protagonists concerning the ban on live concerts and the launch of livestream concerts on the internet. The data collected in the interviews were compared and complemented by information obtained during the documentary research and the bibliographic review, favoring the development of a more realistic description of the case.

\section{Learning objectives}

This case was developed for postgraduate programs (lato or stricto sensu) and can be used in Strategy or Innovation Management courses. The case is particularly relevant for the exploration and debate of concepts related to platform management (Eisenmann, Parker, \& Van Alstyne, 2006; Gorwa, 2019; Parker \& Van Alstyne, 2014; Tiwana, 2013). For that, it is recommended to associate the preparation of the case with the complementary previous reading of "Platform Strategy," by Parker and Van Alstyne (2014). 
The case narrates how a famous Brazilian singer, Diogo Nogueira, and his managers, Anita Carvalho and Afonso Carvalho, are practically 'forced' to adopt an innovation, the distribution of live concerts through internet broadcasts, as a response to the prohibition of in-person presentations to the public. Once the first transmission was carried out, which was successful, the trio assesses what would be the best way to proceed, in view of the perception that uncertainties regarding the regulation, demand, and behavior of the leading streaming platforms could threaten the sustainability of the sponsored lives model. Therefore, the case has the following educational objectives:

- Stimulate the understanding of the main properties of digital platforms, such as multilaterality, network effects, and the consequent potential for user lock-in (Eisenmann et al., 2006);

- Discuss the main growth challenges inherent to digital platforms (Parker \& Van Alstyne, 2014; Tiwana, 2013);

- Discuss strategies to overcome such growth challenges (Parker \& Van Alstyne, 2014).

\section{Discussion questions}

1. Is the sponsored lives model really new? How does it differ from the model used by other types of content distributed by YouTube?

2. In your opinion, are the concerns of Diogo and his managers about the sustainability of the sponsored lives model justified?

3. If you were in the place of Diogo Nogueira and his managers, would you try new formats for marketing lives? Which? Why?

\section{Case analysis}

A comprehensive analysis of the case should include at least four themes: (1) the mapping and exploration of the sponsorship monetization model adopted by lives distributed through YouTube; (2) the identification and discussion of the main risks associated with this model; (3) the reflection on potential impacts generated by changes in the governance of platforms such as YouTube on complementors, such as artists who produce lives; and (4) the debate on alternative models for marketing lives.

\section{(1) Mapping and exploration of the sponsorship monetization model adopted by lives distributed through YouTube}

It is recommended to start the case encouraging students to establish a clear view of the monetization structure adopted by the vast majority of artists who produced lives, pondering how much of this model is really new. In essence, the model adopted by Diogo in his lives follows a platform logic and can be analyzed strategically as such. This fact is suggested by one of the protagonists, Afonso, when he states that "A livestream concert is like a live TV show." TV networks are considered examples of 'two-sided markets,' or platforms, as they connect two different groups of customers, the so-called 'sides': advertisers and viewers (Eisenmann et al., 2006).

Like so many live shows from TV networks, Diogo Nogueira monetizes his livestreams through sponsorships inserted during transmission. Thus, the artist's broadcasts function as platforms that connect two 'sides' - sponsors to viewers (i.e., consumers), as on TV. The difference is that TV shows with live insertions from advertisers are usually produced and marketed by the TV network itself, while livestreams do not have direct participation of streaming platforms in their production, nor in the marketing of sponsorship quotas. In this sense, Diogo Nogueira's livestream concert was monetized following a platform logic operating within another larger platform, such as YouTube (Appendix, Figures 1 and 2). This logic has already been used commonly by content creators (socalled youtubers), who negotiate directly with sponsors to display brands and products within their videos, without intervention by the YouTube platform. It happens that, in these cases, the values typically are much lower than those involved in livestream concerts sponsorships, which can reach around half a million reais. Thus, the accelerated revenue growth associated with the sponsored livestream model, which disintermediates the platform that enables it, can generate conflicts and risks to be explored by the students.

\section{(2) Identification and discussion of the main risks associated with the sponsored lives model}

Uncertainties about the future of lives abound. Debates about charging royalties for music performed in lives are still in their early stages. Likewise, incidents of artists getting intoxicated during lives aroused questions from consumers, advertisers, and authorities about the need for more restrictive regulations on the format, as is already the case with TV shows. In addition, the expressive 
growth in the supply of lives may bring the advertiser and consumer markets closer to a state of saturation.

However, in addition to these risks, there is an issue that must be observed: the high degree of dependence that artists producing sponsored lives have in relation to YouTube, the largest streaming platform in the world, which, in Brazil alone, has about 150 million users.

Services like YouTube are characterized by crossside network effects, dynamics by which each additional user on one 'side' of the platform (e.g., viewers) can make it more attractive to users on the other 'side' (e.g., artists), and vice versa, leading the platform to exponential growth and eventual market domination (Zhao, Von Delft, Morgan-Thomas, \& Bu, 2020). Thus, the 150 million users make YouTube especially attractive to artists producing sponsored lives, to the point that they may be discouraged or even unable to migrate to competing platforms, approaching a situation of great dependency or, at the limit, lock-in (Tiwana, 2013).

Such a dependence of artists in relation to YouTube generates a high risk, since they are subject to changes in the rules of this platform that can compromise the revenue obtained from sponsored lives.

However, it must be considered that this trend of market domination by a single platform is still influenced by the ability of its users to be simultaneously affiliated to multiple platforms, a phenomenon called multihoming (Eisenmann et al., 2006). There are very few restrictions for a viewer to access videos on different platforms, as well as there are few hurdles for an artist to distribute his/her lives also through other channels, such as Instagram or even his/her own app.

Therefore, markets where there are few restrictions on multihoming tend to have fierce competition between leading and incoming platforms. And the competitiveness among platforms, in turn, tends to influence their governance (Parker \& Van Alstyne, 2014), which is explored in the following topic.

\section{(3) Potential impacts of changes in YouTube governance on sponsored lives}

According to Gorwa (2019), governance refers to the rules that define participation, monetization, and access to a platform. An ideal governance is simple, fair, and transparent, to make participants aware of the platform's rules and reduce their risk perception (Tiwana, 2013). New platforms tend to have more 'open' governance, that is, they reduce restrictions to facilitate the access of participants to quickly create a large user base in order to achieve network effects and, therefore, increase their competitiveness. However, overly 'open' governance can reduce the platform's ability to retain value in the exchanges it makes possible between its 'sides' (Parker \& Van Alstyne, 2014).

With this in mind, it should be noted that YouTube monetizes its broadcasts through ads inserted in the videos. Lives, however, generate sources of revenue over which YouTube has little control, such as sponsorships. In this sense, YouTube could make its governance more restrictive, particularly with regard to monetization, requiring that sponsorship deals for lives must be intermediated by YouTube itself, as in traditional ads. There are precedents for this, since YouTube has already made changes to the monetization rules that have reduced the revenue of content producers.

Considering that, if YouTube adopts a more restrictive monetization governance, there may be a 'star drain,' with artists being encouraged to try distributing their lives on other platforms. However, even in the face of a restrictive governance, such artists will not abandon YouTube if they understand there is no comparable alternative for distributing their sponsored lives. Therefore, YouTube's propensity to have a more 'open' (i.e., not charging commissions on sponsorships in lives) or 'restrictive' (i.e., charging commissions on sponsorships) governance reflects how threatened this platform feels by existing or potential competitors.

YouTube is now the largest video platform in the world, which could lead to a more restrictive governance. On the other hand, there are few impairments to the multihoming of viewers, artists, and sponsors, which would accentuate competition among streaming platforms, discouraging YouTube from adopting a more restrictive governance. In addition, there are reports of boycotts of streaming services triggered by the negative perception of artists and their fans about the monetization rules of these platforms, which would suggest that a tightening in these rules could encourage migration to competitors.

This review is not meant to achieve a definitive answer about the future of YouTube governance, but to explore with students the delicate balance that characterizes the relationship between platforms and their multiple 'sides.' From this uncertainty regarding YouTube's governance, the conditions are created to enter the following topic. 


\section{(4) Alternative lives marketing models}

Based on the risks associated with the sponsored lives model and the reports of pioneering artists who have been experimenting with innovative ways to market their concerts via the internet, students should be encouraged to discuss how, if they were in the place of Diogo and his managers, they would proceed with their 'virtual' presentations. The most obvious option is to proceed with the model of sponsored lives distributed on YouTube. It is expected that students present as benefit a greater familiarity of Diogo, Anita, and Afonso with the model. In addition, the case suggests that Diogo Nogueira is a 'brand' that appeals to a broad and loyal audience, facilitating the prospecting of sponsors and the identification of complementary offers, such as Diogo's digital cookbook. It should also be noted that Diogo's first sponsored live was considered a success, earning about 2.5 times the expected revenue from a usual show and accumulating a significant amount of donations.

However, if, on the one hand, the option to continue sponsored lives is familiar and, therefore, free from the risks typically associated with experimenting with innovations, on the other, it does not present answers to uncertainties that threaten its sustainability, such as regulatory risk, dependence on YouTube, or variations in viewers' and sponsors' demand. Therefore, there is room to ponder the attractiveness of alternative models.

The great alternative to the traditional sponsored lives format is the launch of the Clube do Samba, that is, a proprietary app for broadcasting live concerts, something that has been tried by popular foreign artists. The emergence of 'software as a service' providers that offer ready-to-use customizable streaming apps has reduced the costs and complexity once involved in this alternative. Students are expected to address at least three variations of this app, each with its own unique growth challenges, which will be discussed below.

\section{Clube do Samba by subscription}

Some students may favor the creation of the Clube do Samba ("Samba Club”) as a proprietary app for subscription-paid lives, just as the artist Melissa Etheridge has been experimenting with in the North American market. By exempting sponsors, this model would be less subject to regulatory issues or third party interventions (such as YouTube) related to the exposure of brands in their broadcasts.

It should be considered, however, whether this model would be able, at least, to achieve the expected revenue from a sponsored live. Successful lives have obtained sponsorships totaling around $\mathrm{R} \$ 500,000$. A conservative analysis, therefore, would assess how many subscribers Clube do Samba would need to match the maximum revenue obtained by a traditional sponsored live, that is, $\mathrm{R} \$ 500,000$. Although it is not specified how much Clube do Samba would charge for the subscription, it is speculated that the price would be similar to that practiced by competitors such as Spotify, that is, about $\mathrm{R} \$ 15$. Finally, it must be remembered that Clube do Samba must pay $30 \%$ of its revenues to the 'software as a service' provider that developed the app. Thus, it is estimated that the Clube do Samba by subscription should win $(\mathrm{R} \$ 500,000 /[\mathrm{R} \$ 15 * 70 \%])=47,000$ customers to reach the expected revenue for a sponsored live. In short, if Diogo Nogueira's Clube do Samba attracts 47,000 subscribers (or $8 \%$ of the artist's YouTube channel subscribers), a recurring monthly revenue of $\mathrm{R} \$ 500.000$ would be generated, equivalent to the revenue obtained by sponsorships in a single successful live.

Although it is an estimate, this number helps make the challenge that Diogo Nogueira would face when adopting a subscription based model more tangible: to convert roughly $8 \%$ of his YouTube channel subscribers, for whom lives are normally free, into users willing to monthly pay $\mathrm{R} \$ 15$ to access the Clube do Samba, in a market that is showing signs of potential decline in demand. Even assuming that these YouTube subscribers represent the artist's most loyal fans, whose demand for Diogo's lives may remain unchanged, it should be considered that consumers admit paying monthly subscriptions when they receive a considerable amount of content in return.

In addition, even though it is not specified how long it would take to attract 47,000 customers, it is important that the Clube do Samba by subscription attracts users quickly, as it would be relatively simple and quick for a competitor such as YouTube to offer a similar model, partially neutralizing the appeal of the nascent app (Eisenmann et al., 2006). In this sense, it can be considered whether Diogo, alone, would be able to produce enough content in a short period to convince his fans to subscribe and, mainly, to remain in the Clube do Samba.

Thus, it is worth reflecting how Diogo Nogueira could increase the volume of content in his lives app to justify charging subscriptions. One solution would be to 'open' Diogo Nogueira's proprietary app to invite other samba players to participate. In doing so, Diogo would convert the Clube do Samba into a platform, where, on one side, there are viewers, and on the other, samba singers. However, as described by Parker and Van Alstyne (2014), nascent platforms incur the chicken or egg problem, that is, they do not attract users to one of their 'sides' because they do not have users on the other 'side' and vice versa. In its launch, the Clube do Samba would have difficulties in attracting samba singers due to the scarcity of subscribers, 
whereas these subscribers would not be attracted by the insufficiency of samba singers. At this point, it is pertinent to discuss the feasibility of the strategies described by Parker and Van Alstyne (2014) to overcome the chicken or egg problem.

One strategy is to subsidize one side of the platform: subscribers or samba singers. In the case of Clube do Samba, for example, subscribers could be subsidized through discounts or even temporary exemption from payments. The goal would be to generate a large enough subscriber base to, then, attract artists other than Diogo Nogueira, who could be charged for participating in the platform. Such a strategy would have as its main challenge the fact of relying heavily on investments over time necessary for the Clube do Samba to subsidize one of its 'sides,' in order to achieve the cross-side network effect and start its growth trajectory to obtain financial return in the future.

Alternatively, a platform can execute the 'seeding' strategy described by Parker and Van Alstyne (2014), whereby the platform itself acts at least temporarily as a producer of an exclusive service that will later be offered by third parties. Thus, Diogo Nogueira could invite other renowned samba singers to become partners, forming an original 'team' of artists. This 'team' would have enough appeal to encourage consumers to pay subscriptions to access exclusive lives. Again, the challenge would be to convince a sufficiently large number of samba singers to abandon sponsored lives on established platforms to transfer this content to the Clube do Samba. In addition, even if this challenge is overcome, the strategy carries with it another weakness: Diogo would yield a considerable part of the revenues and control of the platform when allowing the entry of partners. If three samba singers were invited, the Clube do Samba would have to attract around $\left(\mathrm{R} \$ 500,000 /\left[\mathrm{R} \$ 15^{*} 70 \% * 0.25\right]\right)=190,000$ subscribers for Diogo to obtain the same revenue generated by a successful sponsored lives.

Finally, the 'piggybacking' strategy (Parker \& Van Alstyne, 2014) should be considered, by which the nascent platform seeks to integrate users of leading platforms. In this sense, Diogo Nogueira could use his sponsored lives on YouTube to promote his Clube do Samba. Thus, part of the lives could be broadcast 'open' (free of charge) on YouTube and another part would be distributed exclusively at Clube do Samba. While it looks promising, it should be noted that this strategy can trigger retaliation from the platform that 'provides' users, especially when it is disproportionately larger than the nascent platform. In addition, there is a risk of dissatisfaction among consumers themselves.

\section{Free Clube do Samba for consumers}

Faced with the challenges of converting lives viewers into subscribers, some students may suggest launching Clube do Samba as a free platform, monetized by sponsorships. However, in doing so, Diogo Nogueira would again be subject to certain risks associated with the lives distributed on YouTube, such as uncertainties regarding the regulation on brand exposure and the demand from sponsors and viewers. And as with the subscription-based alternative, the free Clube do Samba would also face the chicken or egg problem, although in a more complex way, since, in addition to samba singers and viewers, it would also be necessary to attract sponsors. These sponsors, in turn, are only willing to invest amounts close to $\mathrm{R} \$ 500,000$ for lives capable of reaching millions of simultaneous viewers. So, unlike the subscription model where 'only' 47,000 loyal fans were sufficient to match the revenue obtained from lives on YouTube, the Clube do Samba would need around one million viewers, therefore a much larger audience, to attract 'big' sponsors. Such a number could be even greater considering the payment of $30 \%$ of the revenue foreseen to the provider of 'software as a service' that developed the platform.

\section{The pay-per-view Clube do Samba}

Inspired by the initiatives of artists like Billie Eilish, some students can explore Clube do Samba as an app for distribution of Diogo Nogueira's lives in a pay-per-view model. As in a conventional concert, in this model viewers access to lives is obtained by paying a ticket, which, in foreign markets, has been priced at around $\mathrm{R} \$ 100$.

As it consists of a proprietary app that is independent of sponsors, the pay-per-view Clube do Samba would be free from the risks associated with changes in the regulation on brand exposure, changes in YouTube's governance, and variations in demand in the advertising market. And, since viewers only pay when they consume a content, the operating logic of the pay-per-view Clube do Samba can be the opposite of the subscription-based model: instead of an abundance of lives to justify the payment of a monthly fee, a relative scarcity of shows may be desirable to give them the status of premium, unique, and exclusive events, for which the most loyal fans would be willing to pay for tickets.

As a result, the pay-per-view Clube do Samba would be less dependent on the adoption of other samba singers, and may, in the end, consist of a solo initiative by Diogo Nogueira. Thus, at least at its launch, the pay-per-view Clube do Samba would not be configured as a platform or "two-sided market" (Eisenmann, et al., 2006, p. 2), as other artists (a 'side') would not be attracted to enable its operation with fans (the other 'side'). As such, it would not 
be subject to the chicken or egg problem (Parker \& Van Alstyne, 2014) that affects the other alternatives of Clube do Samba discussed.

However, more than in other alternatives, the payper-view Clube do Samba depends fundamentally on the 'star power' of Diogo Nogueira. Assuming the price of R\$ 100 per ticket, as well as the $30 \%$ commission charged by the 'software as a service' provider that offers the system, a show at the pay-per-view Clube do Samba should sell $7,142$ tickets (R\$ $500,000 /[\mathrm{R} \$ 100 * 70 \%])$ to match the expected revenue of a successful sponsored live, equivalent to $1 \%$ of the number of subscribers of Diogo Nogueira's YouTube channel. So, while the pay-per-view Clube do Samba needs to attract a smaller number of fans compared to other alternatives studied, the cost of entry for each fan is also significantly higher.

It should also be reflected if the pay-per-view Clube do Samba could simply coexist with the sponsored lives of YouTube. On the one hand, the music industry traditionally uses free distribution channels to consumers (e.g., radio) to generate demand for live concerts. On the other hand, a way to increase the fans' perceived value regarding the pay-perview Clube do Samba is precisely to make Diogo Nogueira's presentations more exclusive. In this case, the artist would have to achieve a delicate balance where the sponsored lives act as promoters of the pay-per-view Clube do Samba while not reducing its appeal.

Finally, as suggested by Tiwana (2013), any product or service with a large and loyal user base can be converted into a platform. That is, when the pay-per-view Clube do Samba obtains a 'critical mass' of loyal users, it could be converted into a platform by 'opening up' to other samba singers, who could distribute their shows upon payment of commission.

\section{Teaching plan}

The case is versatile and can be discussed in different ways. Therefore, it is recommended that students go through three stages in exploring the case: (a) previous individual reading of the case and complementary texts; (b) small group debate; and (c) plenary discussion (Andersen \& Schiano, 2014; Erskine, Leenders, \& Mauffette-Leenders, 1998). Figure 3 (see Appendix) presents a suggested framework to be developed throughout the debate. Next, a teaching plan is proposed, considering a 90-minute session.

\section{(1) Opening (10 minutes)}

A provocative question to start the discussion is: What business is Diogo Nogueira in? A first reading would suggest that the artist is in the music business. More comprehensive analyses may suggest that Diogo Nogueira is in the entertainment business, or in the media and advertising business. Thereafter, it is recommended that students proceed to the discussion in small groups with two questions for reflection, described below.

\section{(2) Small group discussion (15 minutes)}

The following are suggested questions to guide the discussion in small groups, preparing students for the plenary session: (a) After all, what does Diogo Nogueira offer to the market?; (b) Which are Diogo Nogueira's clients?

These two questions seek to lead the discussion in small groups to the central theme that will be developed in the plenary: Which models can be adopted by Diogo Nogueira to sell his lives?

\section{(3) Plenary (60 minutes)}

This stage should start by mapping and discussing the sponsorship lives model developed in platforms such as YouTube. Then, an interesting way to keep students engaged is to ask them to take a stand: who would remain in the traditional model of lives and who would bet on alternative formats (such as the one based on proprietary apps for shows monetized by subscription or by charging tickets), presenting the respective arguments. This debate favors the exploration of the risks, advantages, and disadvantages involved in each proposed model.

\section{(4) Closure (5 minutes)}

As expected in teaching cases, there are many possible answers for Diogo Nogueira's dilemma. However, it is recommended that the teacher encourage students to, based on the debate held, reflect on whether they would maintain or change their positions regarding the monetization model they would assume for their lives if they were the protagonists. 


\section{REFERENCES}

Andersen, E., \& Schiano, B. (2014). Teaching with cases: A practical guide. Boston: HBS

Eisenmann, T., Parker, G., \& Van Alstyne, M. (2006). Strategies for two-sided markets. Harvard Business Review, 84, 92101+149. Retrieved from https://www.researchgate. net/publication/294221616 Strategies for two-sided $\underline{\text { markets }}$

Erskine, J., Leenders, M. R., \& Mauffette-Leenders, L. (1998). Teaching with Cases. London: Richard Ivey School of Business.

Gorwa, R. (2019). What is platform governance? Information, Communication \& Society, 22, 854-871. https://doi.org/10.1080/1369118X.2019.1573914

\section{Authorship}

\section{Marco Aurelio de Souza Rodrigues}

Escola Superior de Propaganda e Marketing

Rua do Rosário, no 90, Centro, 20041-002, Rio de Janeiro, RJ, Brazil

E-mail address: marco.rodrigues@espm.br

(1) https://orcid.org/0000-0002-9250-4761

\section{Daniel Kamlot*}

Fundaçáo Getulio Vargas, Escola Brasileira de Administração Pública e de Empresas

Rua Jorn. Orlando Dantas, nº 30, Botafogo, 22231-010, Rio de Janeiro, RJ, Brazil

E-mail address: danielkamlot@yahoo.com.br, dkamlot@gmail.com

(1) https://orcid.org/0000-0002-6976-6333

\section{Anita Vasconcelos de Carvalho}

Escola Superior de Propaganda e Marketing

Rua do Rosário, no 90, Centro, 20041-002, Rio de Janeiro, RJ, Brazil

E-mail address: anitacarvalho@me.com

(1) https://orcid.org/0000-0002-5637-8059

${ }^{*}$ Corresponding Author

\section{Funding}

The authors reported that there is no financial support for the research in this article.

\section{Conflict of Interests}

The authors have stated that there is no conflict of interest.

\section{Copyrights}

RAC owns the copyright to this content.
Parker, G. \& Van Alstyne, M. W. (2014). Platform Strategy. The Palgrave Encyclopedia of Strategic Management. https://doi.org/10.2139/ssrn.2439323

Tiwana, A. (2013). Platform Ecosystems: Aligning Architecture, Governance, and Strategy. Burlington, MA: Morgan Kaufmann.

Zhao, Y., Von Delft, S., Morgan-Thomas, A., Buck, T. (2020). The evolution of platform business models: Exploring competitive battles in the world of platforms. Long Range Planning, 53(4), 101892. https://doi.org/10.1016/j.lrp.2019.101892

\section{Authors' Contributions}

$1^{\text {st }}$ author: conceptualization (equal); formal analysis (equal); investigation (equal); methodology (equal); validation (equal); visualization (equal); writing-original draft (equal); writing-review $\&$ editing (equal).

$2^{\text {nd }}$ author: conceptualization (equal); formal analysis (equal); investigation (equal); methodology (equal); project administration (equal); resources (equal); supervision (equal); validation (equal); visualization (equal); writing-original draft (equal); writing-review \& editing (equal).

$3^{\text {rd }}$ author: conceptualization (equal); formal analysis (equal); investigation (equal); methodology (equal); project administration (equal); validation (equal); visualization (equal); writing-original draft (equal); writing-review \& editing (equal).

\section{Plagiarism Check}

The RAC maintains the practice of submitting all documents approved for publication to the plagiarism check, using specific tools, e.g.: iThenticate.

\section{Peer Review Method}

This content was evaluated using the double-blind peer review process. The disclosure of the reviewers' information on the first page, as well as the Peer Review Report, is made only after concluding the evaluation process, and with the voluntary consent of the respective reviewers and authors.

\section{Data Availability}

RAC encourages data sharing but, in compliance with ethical principles, it does not demand the disclosure of any means of identifying research subjects, preserving the privacy of research subjects. The practice of open data is to enable the reproducibility of results, and to ensure the unrestricted transparency of the results of the published research, without requiring the identity of research subjects. 


\section{APPENDIX A.}

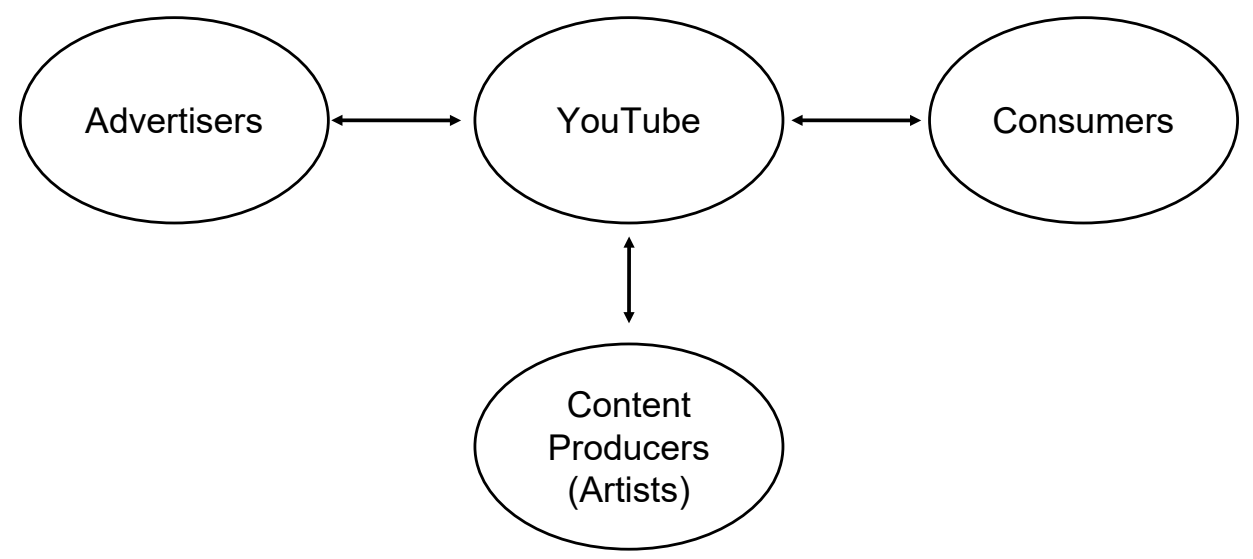

Figure A1. YouTube platform traditional model.

Source: The authors.

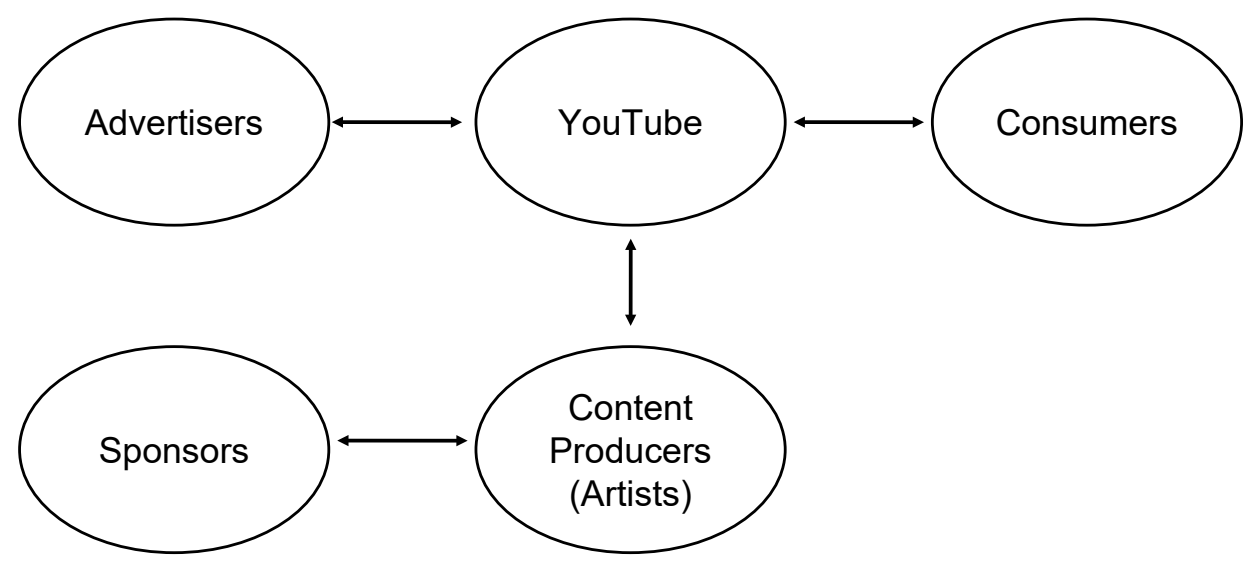

Figure A2. YouTube platform model for sponsored livestream concert.

Source: The authors. 


\section{What business is}

Diogo Nogueira in?

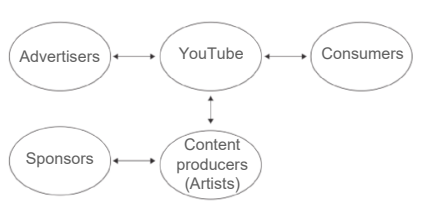

Is the sponsored livestream model really new?

- Livestreams as TV Shows

- Livestreams as platforms

- Ad-based and subscription based monetization

- But...

- TV networks control production and sponsorship deals, capturing

value... while...

- YouTube has little control over production and sponsorship deals regarding livestreams
What are the associated risks with livestreams broadcasted through YouTube?

- Rights management

- Changes in regulation over

brand exposure

- Variation in consumer demand

- Variation in sponsors demand

- Changes in YouTube rules regarding content production and sponsorship of livestreams

What could encourage YouTube to modify or keep its rules?

- Capture a bigger share of the value created through sponsorships of livestreams

- Avoid "star drain" towards competing platforms

- Chance of multihoming for viewers, artists and sponsors

- Competitiveness among streaming platforms

\section{Monetization Models for Lives: Pros \& Cons}

Sponsored Livestreams on

\section{YouTube}

- Pros

- Familiarity

- Diogo Nogueira as a "brand"

- Complementary offers (cookbook)

- Cons

- Regulation over brand exposure

- Variation in consumers' and

sponsors' demand

- Changes in YouTube rules

\section{Clube do Samba: Subscription}

- Pros

- Less regulatory risk over brand exposure

- No risk related to changes in YouTube rules

- Cons

- Needs to attract thousands of subscribers used to free livestreams (47k)

- Needs huge amount of content

- Chicken or Egg problem - Strategies to beat the Chicken or Egg Problem:

- Subsidize? Seeding?

- Piggybacking?

\section{Clube do Samba: Free}

- Pros

More appealing to viewers

- Cons

- Needs to attract millions of viewers

- Needs huge amount of content

- Chicken or Egg problem

- Regulation over brand exposure

- Variation in consumers' and sponsors' demand

\section{Clube do Samba: Pay-per-view}

- Pros

- No regulatory risk over brand exposure

- No risk related to changes in YouTube rules

- No need for sponsors

- Doesn't need much content

- No Chicken or Egg problem

- Potential coexistence with

YouTube sponsored livestreams?

- Cons

- Convert thousands of viewers used to free livestreams into paying customers of expensive tickets (7k paying US\$25/ticket)

Figure A3. Suggested board plan.

Source: The authors. 